\title{
FOXL2 molecular testing in ovarian neoplasms: diagnostic approach and procedural guidelines
}

Stefan Kommoss ${ }^{1}$, Michael S Anglesio ${ }^{1}$, Robertson Mackenzie ${ }^{2}$, Winnie Yang ${ }^{2}$, Janine Senz ${ }^{2}$, Julie $\mathrm{Ho}^{2}$, Lynda Bell ${ }^{2}$, Sylvia Lee ${ }^{2}$, Julie Lorette ${ }^{2}$, David G Huntsman ${ }^{1,2}$ and C Blake Gilks ${ }^{1}$

${ }^{1}$ Department of Pathology and Laboratory Medicine, University of British Columbia, Vancouver, BC, Canada and ${ }^{2}$ Center for Translational and Applied Genomics, Department of Pathology, Vancouver, BC, Canada

A single, recurrent somatic point mutation $(402 C \rightarrow G)$ in FOXL2 has been described in almost all adult-type granulosa cell tumors but not other ovarian neoplasms. Histopathological features of adult-type granulosa cell tumors can be mimicked by a variety of other tumors, making diagnosis of adult-type granulosa cell tumor challenging. It has been suggested that molecular testing for FOXL2 mutation might be a useful tool in the diagnosis of adult-type granulosa cell tumors. The aim of this study was to demonstrate how testing for the FOXL2 mutation can be used in a gynecological pathology consultation service and to establish clear procedural guidelines for FOXL2 testing. Immunohistochemistry for FOXL2 was done using an anti-FOXL2 polyclonal antiserum. If immunohistochemistry was positive, FOXL2 mutation status was subsequently analyzed using a TaqMan assay. A dilution experiment was done to assess the sensitivity and minimum tumor cellularity requirements for our TaqMan assay. Twenty problematic cases were assessed, where the differential diagnosis after the initial investigations included adult-type granulosa cell tumors. Differential diagnoses included: thecoma, Sertoli-Leydig cell tumor, juvenile granulosa cell tumor, endometrial stromal sarcoma and others. In all cases, FOXL2 immunohistochemistry was positive and in six samples the FOXL2 mutation was detected, thus confirming a diagnosis of adult-type granulosa cell tumor. The TaqMan assay was able to reliably detect the FOXL2 mutation with input DNA in the range of $2.5-20 \mathrm{ng}$, and with a minimum of $25 \%$ tumor cell nuclei. The analysis of the FOXL2 mutational status in clinical samples is a useful diagnostic tool in situations where the differential diagnosis is between adult-type granulosa cell tumor and other ovarian tumors. The TaqMan assay requires a minimum of $2.5 \mathrm{ng}$ DNA, with optimal assay performance for 5 to $10 \mathrm{ng}$ DNA input. Laser capture or needle-macrodissection should be undertaken to enrich samples with tumor cell content below $25 \%$.

Modern Pathology (2013) 26, 860-867; doi:10.1038/modpathol.2012.226; published online 25 January 2013

Keywords: adult-type granulosa cell tumor; FOXL2; immunohistochemistry; mutation analysis; ovarian neoplasms; Taqman

Adult-type granulosa cell tumors account for 1-2\% of all ovarian neoplasms and for $<10 \%$ of ovarian malignancies. They are the most common malignant sex cord stromal tumor. Even though adult-type granulosa cell tumors usually present at early stage, recurrence is not uncommon and can be 5-30 years from the original intervention, suggesting that longterm follow-up is warranted. Prognosis is generally favorable with a 10 -year survival rate of $60-90 \%$.

Correspondence: Dr CB Gilks, MD, Deparment of Pathology, Vancouver General Hospital, 855 West 12th Avenue, Vancouver, BC, Canada V5Z 1M9.

E-mail: Blake.Gilks@vch.ca

Received 1 September 2012; revised 20 November 2012; accepted 22 November 2012; published online 25 January 2013
Beyond surgery there is no curative treatment available at present. Microscopically, many different architectural patterns can be seen. The most distinctive pattern, microfollicular architecture with Call-Exner bodies, is seen in a minority of cases, and the architectural growth patterns can overlap with those seen in other ovarian tumor types. Cytologically, adult-type granulosa cell tumors are characterized in most cases by scant cytoplasm, very uniform nuclei with inconspicuous nucleoli, and nuclear grooves, but there is considerable case-tocase variation with respect to all of these features. Thus, the morphological features of adult-type granulosa cell tumors can be mimicked by a variety of other tumors, making histopathological assessment challenging, especially in cases with atypical or 
unconventional appearance. Recently a single, recurrent somatic $402 \mathrm{C} \rightarrow \mathrm{G}$ missense point mutation in the Forkhead box protein L2 (FOXL2) was found in tumor samples from patients with adult-type granulosa cell tumors. $^{1}$ It has been shown that the mutation is present in virtually all adult-type granulosa cell tumors and rarely, if ever, occurs in any other tumor type ${ }^{2}$ thus it effectively defines adult-type granulosa cell tumors. Importantly, it is not found in SertoliLeydig cell tumor, juvenile granulosa cell tumor, endometrial stromal sarcoma, follicular cyst or other tumors that can enter the differential diagnosis.

In addition to characterizing the FOXL2 mutation, we have also been able to show that the use of an immuno-panel, including FOXL2 immunostaining, in conjunction with molecular testing for the FOXL2 $(402 \mathrm{C} \rightarrow \mathrm{G})$ mutation has the potential to serve as a diagnostic aid in ovarian tumor pathology. ${ }^{3}$ It was the aim of this study to demonstrate how testing for the FOXL2 mutation can be used in a gynecological pathology consultation service in which diagnostic algorithms were applied to prospectively collected cases.

Molecular testing is highly dependent on DNA extraction procedures as well as DNA input concentrations used. The necessity of macro- or even lasercapture microdissection of tissue samples prior to DNA extraction, in particular, is an important question as specialized laser dissection equipment, and appropriate training on this instrumentation, is not available in many molecular pathology laboratory settings. To address these critical issues and in order to establish some clear procedural guidelines we performed a comprehensive FOXL2 dilution experiment, with the results presented herein.

\section{Materials and methods}

\section{Tissue Samples}

All cases included in this study were submitted to our gynecological pathology consultation service. The initial investigations were done at Royal Jubilee Hospital, Vancouver Island BC, North Shore University Hospital, Manhassett NY, Lion's Gate Hospital, North Vancouver BC, University of Calgary Hospital, Calgary AB, Foothills Medical Centre, Calgary AB, Sunnybrook Health Science Centre, Toronto ON, Hôpital Notre-Dame Hospital, Hearst ON, University of Alberta Hospital, Edmonton AB, Calgary Laboratory Services, Calgary AB, Memorial Sloan-Kettering Cancer Center, New York NY, or through the general surgical pathology service at Vancouver General Hospital, Vancouver BC.

\section{Diagnostic Algorithm}

After an initial morphologic screening was done, immunohistochemistry for FOXL2 was performed. If the immunostaining results were positive, FOXL2 mutation status was analyzed subsequently. The results were then used to exclude adult-type granulosa cell tumor from the list of differential diagnoses in cases negative for the C134W FOXL2 mutation.

\section{Immunohistochemistry}

Immunoperoxidase studies were carried out on paraffin sections of $4 \mu \mathrm{m}$ thickness that were stained using an automated Ventana Discovery XT instrument (Ventana Medical Systems, Tucson, AZ, USA). Epitope retrieval was done on the Ventana Discovery XT by heating the slides for $60 \mathrm{~min}$ in CC1 standard buffer (Ventana Medical Systems). The primary antibody was polyclonal FOXL2-antiserum (1:200; Imgenex, San Diego, CA, USA). Tissue sections were incubated with the primary antibody for $1 \mathrm{~h}$ at room temperature followed by a 30-min incubation with the secondary antibody (unconjugated rabbit antigoat, Jackson ImmunoResearch Labs, West Grove, PA, USA) at 1:300. The tertiary antibody was the prediluted Ventana DAB UltraMap anti-rabbit horseradish peroxidase that was incubated for $16 \mathrm{~min}$. Immunostaining for FOXL2 was scored as either negative or positive, based on the absence or presence of nuclear staining, respectively. The presence of any nuclear staining, regardless of intensity or focality, was considered to be positive.

\section{Molecular Testing for FOXL2 $(402 \mathrm{C} \rightarrow \mathrm{G})$}

The presence of the FOXL2 $(402 \mathrm{C} \rightarrow \mathrm{G})$ mutation was determined by using a TaqMan real-time PCR-based allelic discrimination assay (Applied Biosystems). ${ }^{1}$ In brief, six $0.6 \mathrm{~mm}$ cores were taken from formalinfixed paraffin blocks in tumor rich areas of cases with sufficient tumor content. In cases with widely dispersed tumor cell nests or minimal tumor content only, macro/microdissection was performed prior to DNA extraction by either using a scalpel (macrodissection) or employing laser capture microdissection on a Veritas Microdissection Instrument. In the case of the dilution experiment (see below), $10-\mu \mathrm{m}$ tissue scrolls with near $100 \%$ tumor nuclei were used for DNA extraction. Tissue samples were deparaffinized and DNA was extracted using the Ambion Recover All Total Nucleic Acid Isolation Kit.

Reaction volume of $5 \mu \mathrm{l}$ was used for each replicate well including $2.5 \mu \mathrm{l} 2 \mathrm{X}$ TaqMan master mix (Life Technologies), $0.25 \mu \mathrm{l} 20 \times$ custom synthesized allelic discrimination primer/probe mix (Life Technologies), $2 \mu \mathrm{l}$ DNA (standard input of $20 \mathrm{ng}$ was adjusted as per Figure 2), and water.

\section{Dilution Experiment}

A 384-well format dilution experiment was undertaken that allowed the study of decreasing paraffin block tumor content and different allelic 
discrimination assay total DNA input values at the same time. Tumor DNA that was known to be FOXL2-positive $100 \%$ tumor, heterozygous mutation) was diluted with FOXL2-negative DNA to simulate different tumor to non-tumor nuclei ratios within a tissue sample. Qubit Fluorometric Quantitation was used to ensure highly accurate measurements of double-stranded DNA concentration. The experiment included three different cases, all reactions run in duplicate and each experiment for each sample was repeated three times. Two samples were run at the CTAG lab, BCCA on an ABI7900 instrument in allelic discrimination mode and one sample was run at the Robert HN Ho Research Centre, VCHRI, on a Life-Technologies Viia 7 instrument in allelic discrimination mode. Controls for each run included 20 non-FOXL2 mutant formalin-fixed, paraffin-embedded tissue DNA samples as negative controls as well as no template controls (water only) for each dilution series.

Thresholds for successful PCR amplification was 10 standard deviations from the maximum of the fluorescence signal from the no template control wells along either the X (FAM; wild-type) or Y (VIC; mutant) axis: 0.29 and 0.47 , respectively. As a rule, we consider any run with no template controls falling outside of 2 standard deviations from the mean of no template controls (along either axis) to be contaminated and therefore would repeat the entire run; no such cases were recorded in this study. Threshold for a mutation-positive result was set at 2 standard deviations from the mean of the negative control (wild-type) samples ( $Y$-axis/VIC signal $>0.32)$ as well as outside the thresholds for amplification noted above. As varying instruments and synthesis of probes may influence reporter signals any centre establishing this protocol is strongly advised to re-establish local thresholds using know positives and negatives with each new batch of primers and probes as well as including positive and negative controls in each run assay.

\section{Results}

\section{Gynecological Pathology Consultation Service}

Since FOXL2 $(402 \mathrm{C} \rightarrow \mathrm{G})$ was characterized by our group in 2009, 20 cases have subsequently been submitted for FOXL2 mutation testing through the Vancouver General Hospital Gynecological Pathology consultation service. In addition to a possible diagnosis of adult-type granulosa cell tumor, differential diagnoses included thecoma, Sertoli-Leydig cell tumor, juvenile granulosa cell tumor, endometrial stromal sarcoma, follicular cyst, fibrothecoma, high-grade serous ovarian carcinoma and cellular mitotically active fibroma (Table 1). All samples were stained for FOXL2 expression by immunohistochemistry and, except for one case where the immunohistochemistry staining result was equivocal, all cases showed strong nuclear FOXL2 expression. All samples were then tested for the prototypical adult-type granulosa cell tumor FOXL2 mutation $(402 \mathrm{C}>\mathrm{G})$ using a TaqMan-based PCR/ allelic discrimination assay, three of which were microdissected prior to DNA extraction. Six samples were found to be positive for the mutation. In three of these cases a diagnosis other than adult-type granulosa cell tumor was seriously considered based on $\mathrm{H} \& \mathrm{E}$ and routine immunostaining. For two of these cases, the differential diagnosis rested between thecoma and adult-type granulosa cell tumor; FOXL2 mutation positivity in these cases supports the diagnosis of adult-type granulosa cell tumor. Figure 1 shows two cases where the differential diagnosis was between adult-type granulosa cell tumor and thecoma. FOXL2 mutational testing supported a diagnosis of adult-type granulosa cell tumor in one case, whereas it was excluded in the other case. In the third case, the differential diagnosis rested between high-grade serous carcinoma and anaplastic adult-type granulosa cell tumor (Figure 2). This patient had a past history of adulttype granulosa cell tumor but based on the cellular pleomorphism and strong diffuse p53 immunoreactivity, with negative inhibin immunostaining, this

Table 1 Differential diagnoses, FOXL2 immunohistochemistry and mutational status

\begin{tabular}{|c|c|c|c|}
\hline & $\begin{array}{l}\text { Differential diagnosis } \\
\text { (in addition to adult- } \\
\text { type granulosa cell } \\
\text { tumors) }\end{array}$ & $\begin{array}{l}\text { FOXL2 } \\
\text { immunohistochemistry }\end{array}$ & $\begin{array}{l}\text { FOXL2 } \\
\text { mutational } \\
\text { status }\end{array}$ \\
\hline 1 & Thecoma & Positive & Heterozygous \\
\hline 2 & $\begin{array}{l}\text { Juvenile granulosa } \\
\text { cell tumor }\end{array}$ & Positive & Wild type \\
\hline 3 & $\begin{array}{l}\text { Sertoli-Leydig cell } \\
\text { tumor }\end{array}$ & Positive & Wild type \\
\hline 4 & $\begin{array}{l}\text { Juvenile granulosa } \\
\text { cell tumor }\end{array}$ & Positive & Wild type \\
\hline 5 & Thecoma & Positive & Heterozygous \\
\hline 6 & $\begin{array}{l}\text { Endometrial stromal } \\
\text { sarcoma }\end{array}$ & Positive & Wild type \\
\hline 7 & Serous cystadenoma & Positive & Wild type \\
\hline 8 & $\begin{array}{l}\text { Juvenile granulosa } \\
\text { cell tumor }\end{array}$ & Positive & Wild type \\
\hline 9 & N.A. & Positive & Wild type \\
\hline 10 & N.A. & Equivocal & Wild type \\
\hline 11 & $\begin{array}{l}\text { Cystadenoma from } \\
\text { rete ovarii }\end{array}$ & Positive & Wild type \\
\hline 12 & N.A. & Positive & Homozygous \\
\hline 13 & N.A. & Positive & Heterozygous \\
\hline 14 & $\begin{array}{l}\text { Cellular mitotically } \\
\text { active fibroma }\end{array}$ & Positive & Wild type \\
\hline 15 & $\begin{array}{l}\text { Undifferentiated } \\
\text { sarcoma }\end{array}$ & Positive & Wild type \\
\hline 16 & N.A. & Positive & Wild type \\
\hline 17 & $\begin{array}{l}\text { High-grade serous } \\
\text { ovarian carcinoma }\end{array}$ & Positive & Heterozygous \\
\hline 18 & Thecoma & Positive & Wild type \\
\hline 19 & $\begin{array}{l}\text { Cellular mitotically } \\
\text { active fibroma }\end{array}$ & Positive & Wild type \\
\hline 20 & Sertoli cell tumor & Positive & Heterozygous \\
\hline
\end{tabular}




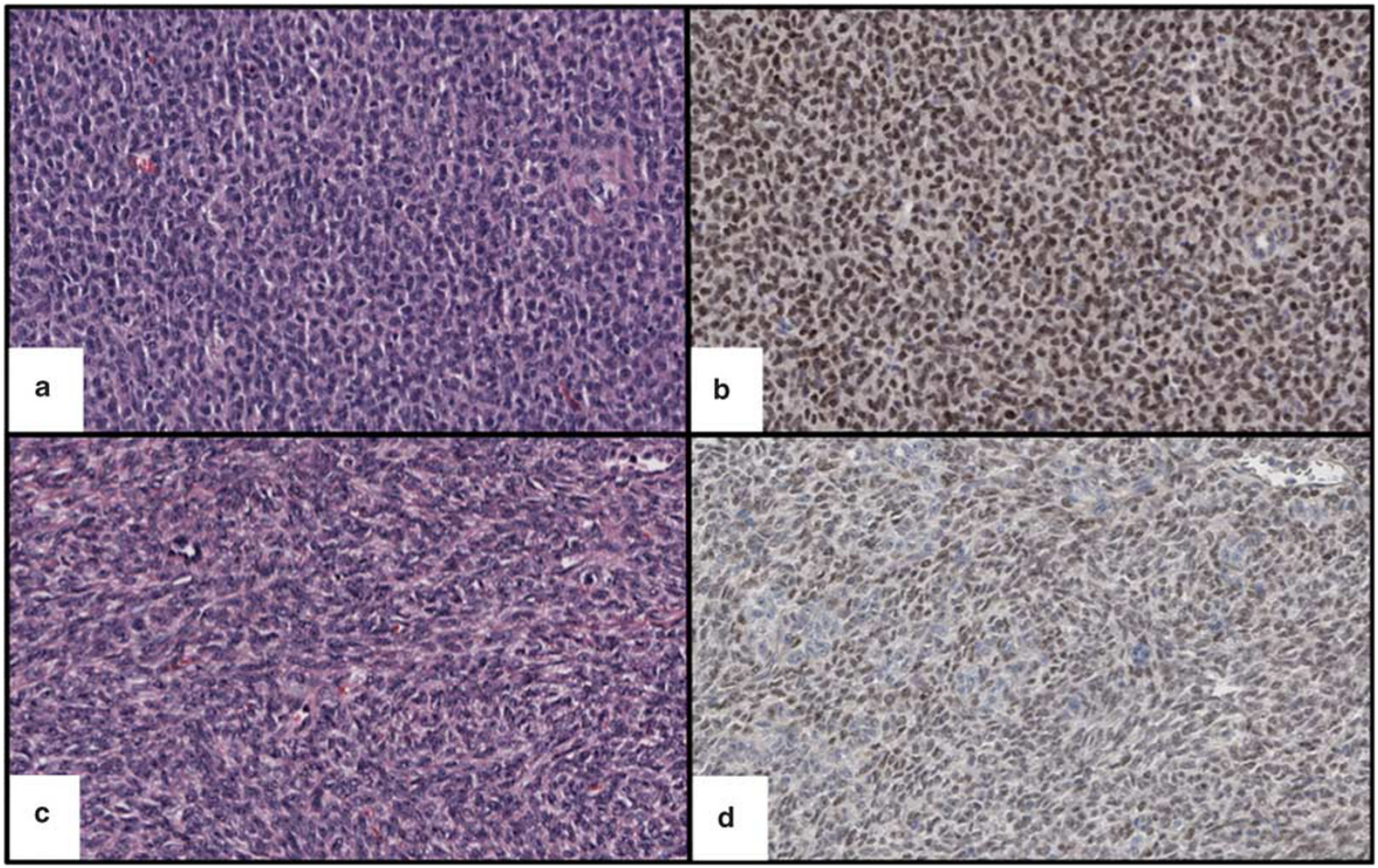

Figure 1 Two cases with differential diagnoses of thecoma vs adult-type granulosa cell tumor. (a, b) H\&E + FOXL2 immunohistochemistry in a case where adult-type granulosa cell tumor was confirmed based on FOXL2 mutation status. (c, d) H\&E + FOXL2 immunohistochemistry in a case where a diagnosis of adult-type granulosa cell tumor was excluded due to the absence of FOXL2 mutation. In both cases clinical and morphological features, including FOXL2 immunostaining, were not able to definitely support one or the other diagnosis.

tumor was initially thought to be a second primary, that is, high-grade serous carcinoma. FOXL2 immunostaining was strongly positive, and FOXL2 mutation testing was also positive, confirming that this was a recurrence of this patient's previously diagnosed adult-type granulosa cell tumor, with emergence of significant cytological pleomorphism since the time of original diagnosis, 2 years previously. p53 mutational testing confirmed the presence of the same somatic p53 mutation in both the current sample, of recurrent adult-type granulosa cell tumor, and the original adult-type granulosa cell tumor specimen from 2010.

\section{FOXL2 Mutation Testing Technical Guidelines}

Testing for FOXL2 mutations are typically done with Sanger sequencing, which may be subject to specific fixation artifacts ${ }^{4}$ and with sensitivity hindered by moderate-to-low tumor content. Our group has therefore used a digital TaqMan allelic discrimination assay for FOXL2 mutation testing. To specifically address the technical limitations of our mutation testing procedure and highlight where basic or specialized microdissection may be required we undertook a dilution matrix experiment. The FOXL2 dilution experiment was set up in a way to simulate decreasing paraffin block tumor nuclear contents of 100, 50, 25, 12.5, 6.25, and $3.125 \%$, represented by serial dilution of FOXL2-positive tumor DNA with FOXL2 wild-type DNA $(1: 2,1: 4,1: 8,1: 16,1: 32)$, with both DNA samples derived from formalin-fixed, paraffinembedded source tissue. Different total DNA input values of $80,60,40,20,10,5$, and $2.5 \mathrm{ng}$ were studied at the same time (Figure 3). In reality it is virtually impossible to have an assured $100 \%$ tumor sample without any infiltrating cells therefore although we used tumor rich samples as ' $100 \%$ ' our dilution matrix in fact represents a slightly lower than reported tumor content. This discrepancy should serve to add confidence to our recommended guidelines (discussed below). Our dilution matrix representing multiple DNA inputs and mutation-positive tumor contents showed a high degree of variability overall (Figure 4a), suggesting specific guidelines should be employed for consistent results. For tumor content of at least $25 \%$ and DNA input from 2.5 to $20 \mathrm{ng}$, the allelic discrimination assay was able to reliably detect the FOXL2 mutation; however, the assay performed best, with no failed reactions, at DNA input quantity of either 5 or $10 \mathrm{ng}$ (Figure 4b). If tumor content was 


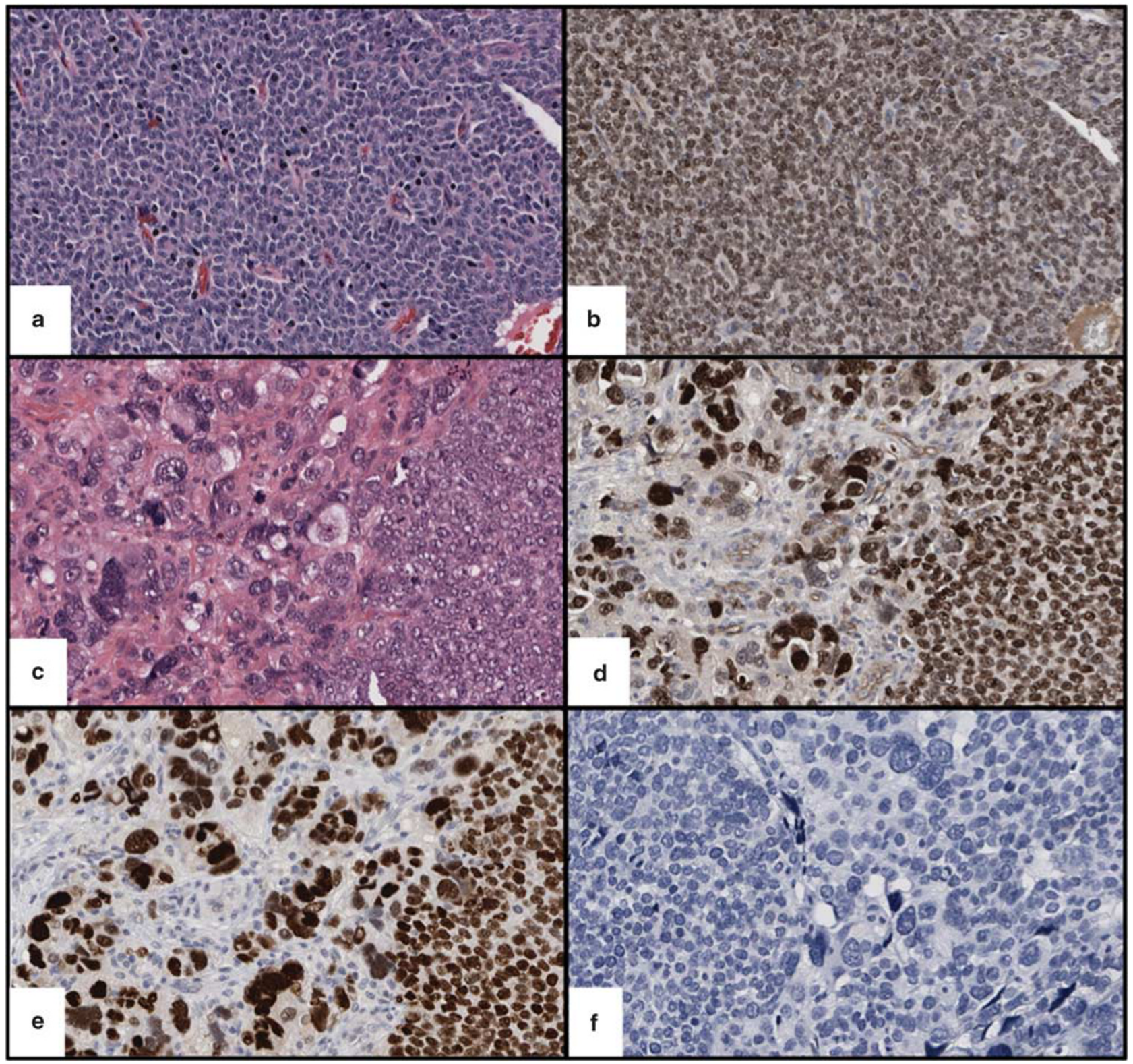

Figure 2 Differential diagnosis between high-grade serous ovarian carcinoma and anaplastic adult-type granulosa cell tumor. (a, b) H\&E and FOXL2 immunostaining in the original adult-type granulosa cell tumor. (c, d) H\&E and FOXL2 immunostaining in the relapse case that was initially thought to be a second primary due to cellular pleomorphism, strong diffuse p53 immunoreactivity (e) and negative inhibin staining (f).

below $25 \%$, there was a reasonable likelihood of false-negative results, while for DNA input quantities of $>20 \mathrm{ng}$ results were inconsistent, yielding false-negative and frequent PCR failure (Figure 3).

\section{Discussion}

The FOXL2 $(402 \mathrm{C} \rightarrow \mathrm{G})$ point mutation has been confirmed to be both a sensitive assay and highly specific to adult-type granulosa cell tumors. ${ }^{1-3,5-7}$ To date PubMed indexed reports cite a total of 290 adult-type granulosa cell tumors that have been tested for the FOXL2 mutation of which 267 (92\%) were positive for the FOXL2 $(402 \mathrm{C} \rightarrow \mathrm{G})$ mutation. The percentage of FOXL2 $(402 \mathrm{C} \rightarrow \mathrm{G})$ mutationpositive cases has consistently been reported to be within the range of 90-97\%, with the exception of one study by D'Angelo et al. ${ }^{8}$ who reported only $70 \%$ of adult-type granulosa cell tumors to be positive. We suggest the possibility that the D'Angelo et al. cohort, consisting of challenging cases drawn from an international consultation practice, included several non-adult-type granulosa cell tumors tumors, resulting in an unexpectedly higher rate $(30 \%)$ of FOXL2-negative adult-type granulosa cell tumors. In addition to possible misdiagnoses, mutation-positive cases may have 
total DNA input

\begin{tabular}{|c|c|c|c|c|c|c|c|}
\hline & $80 \mathrm{ng}$ & 60 ng & $40 \mathrm{ng}$ & $20 \mathrm{ng}$ & $10 \mathrm{ng}$ & $5 \mathrm{ng}$ & $2.5 \mathrm{ng}$ \\
\hline $100 \%$ & $\begin{array}{l}0 \% \text { FN } \\
0 \% \text { FR }\end{array}$ & $\begin{array}{l}0 \% \text { FN } \\
31 \% \text { FR }\end{array}$ & $\begin{array}{l}0 \% \text { FN } \\
13 \% \text { FR } \\
\end{array}$ & $\begin{array}{l}0 \% \mathrm{FN} \\
6 \% \mathrm{FR} \\
\end{array}$ & $\begin{array}{l}0 \% \text { FN } \\
0 \% \text { FR } \\
\end{array}$ & $\begin{array}{l}0 \% \text { FN } \\
0 \% \text { FR } \\
\end{array}$ & $\begin{array}{l}0 \% \mathrm{FN} \\
6 \% \mathrm{FR}\end{array}$ \\
\hline $50 \%$ & $\begin{array}{c}0 \% \text { FN } \\
50 \% \text { FR }\end{array}$ & $\begin{array}{l}11 \% \text { FN } \\
33 \% \text { FR }\end{array}$ & $\begin{array}{c}0 \% \text { FN } \\
13 \% \text { FR }\end{array}$ & $\begin{array}{l}0 \% \text { FN } \\
0 \% \text { FR }\end{array}$ & $\begin{array}{l}0 \% \text { FN } \\
0 \% \text { FR }\end{array}$ & $\begin{array}{l}0 \% \text { FN } \\
0 \% \text { FR }\end{array}$ & $\begin{array}{l}0 \% \text { FN } \\
0 \% \text { FR }\end{array}$ \\
\hline $25 \%$ & $\begin{array}{c}0 \% \text { FN } \\
50 \% \text { FR }\end{array}$ & $\begin{array}{l}17 \% \text { FN } \\
67 \% \text { FR } \\
\end{array}$ & $\begin{array}{l}44 \% \mathrm{FN} \\
6 \% \mathrm{FR} \\
\end{array}$ & $\begin{array}{l}0 \% \text { FN } \\
0 \% \text { FR } \\
\end{array}$ & $\begin{array}{l}0 \% \text { FN } \\
0 \% \text { FR }\end{array}$ & $\begin{array}{l}0 \% \text { FN } \\
0 \% \text { FR } \\
\end{array}$ & $\begin{array}{l}0 \% \text { FN } \\
0 \% \text { FR }\end{array}$ \\
\hline $12.5 \%$ & $\begin{array}{l}25 \% \text { FN } \\
67 \% \text { FR } \\
\end{array}$ & $\begin{array}{l}67 \% \text { FN } \\
33 \% \text { FR } \\
\end{array}$ & $\begin{array}{l}83 \% \text { FN } \\
11 \% \text { FR } \\
\end{array}$ & $\begin{array}{l}0 \% \text { FN } \\
0 \% \text { FR }\end{array}$ & $\begin{array}{l}39 \% \mathrm{FN} \\
0 \% \mathrm{FR} \\
\end{array}$ & $\begin{array}{l}\% \text { FN } \\
0 \% \text { FR } \\
\end{array}$ & $\begin{array}{l}6 \% \text { FN } \\
0 \% \text { FR }\end{array}$ \\
\hline $6.25 \%$ & $\begin{array}{l}33 \% \text { FN } \\
67 \% \text { FR } \\
\end{array}$ & $\begin{array}{l}61 \% \text { FN } \\
39 \% \text { FR } \\
\end{array}$ & $\begin{array}{l}72 \% \text { FN } \\
28 \% \text { FR } \\
\end{array}$ & $\begin{array}{l}0 \% \mathrm{FN} \\
6 \% \mathrm{FR} \\
\end{array}$ & $\begin{array}{c}56 \% \text { FN } \\
0 \% \text { FR } \\
\end{array}$ & $\begin{array}{l}22 \% \text { FN } \\
0 \% \text { FR } \\
\end{array}$ & $\begin{array}{c}50 \% \text { FN } \\
0 \% \text { FR } \\
\end{array}$ \\
\hline $3.125 \%$ & $\begin{array}{l}33 \% \text { FN } \\
67 \% \text { FR } \\
\end{array}$ & $\begin{array}{l}61 \% \text { FN } \\
39 \% \text { FR } \\
\end{array}$ & $\begin{array}{l}83 \% \mathrm{FN} \\
17 \% \mathrm{FR} \\
\end{array}$ & $\begin{array}{l}0 \% \mathrm{FN} \\
6 \% \mathrm{FR} \\
\end{array}$ & $\begin{array}{l}94 \% \mathrm{FN} \\
6 \% \mathrm{FR} \\
\end{array}$ & $\begin{array}{l}67 \% \text { FN } \\
0 \% F R\end{array}$ & $\begin{array}{l}78 \% \text { FN } \\
0 \% \text { FR } \\
\end{array}$ \\
\hline
\end{tabular}

Figure 3 Layout of dilution experiment to look at decreasing paraffin block tumor cellularity as well as different total DNA input values. DNA was serially diluted with water along the $X$-axis and with mutation-negative DNA along the $Y$-axis. False-negative (FN) and failed reaction (FR) rates are given for each DNA input/tumor ratio. Cells in green indicate assay input values resulting in neither failed reactions nor false-negative results, whereas yellow-coded cells flag failed reactions, red cells indicate where some false-negative result was seen.

been overlooked due to technical limitations of Sanger sequencing, which is prone to fixation artifacts $^{4}$ and may be affected by low tumor cellularity/proportion of tumor nuclei. Thus, technical limitations, including low tumor content, and modestly insensitive molecular assays, may lead to apparently mutation-negative adult-type granulosa cell tumor cases.

Our group has developed a high sensitivity digital TaqMan allelic discrimination assay, which we consider to be the new gold standard for FOXL2 mutation detection. Sanger sequencing has been used extensively as the standard for mutational analysis, however, in the context of testing a case for the presence or absence for the FOXL2 mutation the TaqMan assay provides clear binary results, eliminates the bias introduced through interpretation of Sanger data and at the same time is less labor intensive and more cost effective. It was our aim to provide clear procedural guidelines for the use of this assay.

Based on the results of our dilution matrix we recommend DNA input quantities from 5 to $10 \mathrm{ng}$ and a minimum of $25 \%$ tumor cell nuclei (tumor cellularity) in the sampled tissue for accurate testing. Using these criteria we have achieved highly reproducible results with DNA extracted from 'realworld' formalin-fixed paraffin-embedded clinical samples. Outside the latter recommendations there was a reasonable likelihood for false-negative or assay failures, overall yielding inconsistent results.

As spectrophotometric measures of DNA concentration are affected by contaminants like RNA carried over through nucleic acid extraction and other cyclic-organic molecules absorbing light at similar wavelength to DNA, ${ }^{9,10}$ we further recommend the widely available fluorometric assessment methods specific for double-strand DNA (dsDNA) using binding dyes such as picogreen or those used with the Quant-iT dsDNA Broad-Range Assay kit employed in this study. We also showed that elevating the amount of input DNA did not reliably restore test sensitivity in test samples with $<25 \%$ tumor nuclei. This indicates that if only tumor blocks with overall tumor nuclei content of $<25 \%$ are available then enrichment of tumor content via macro/microdissection should be employed prior to DNA extraction.

The current study found 6/20 (30\%) of cases submitted in consultation for FOXL2 mutation testing to be positive, which confirms a diagnosis of adult-type granulosa cell tumor in these cases. Cases without and with the mutation in this case series showed overlap in morphological features, thus the utility of this assay. The majority of adulttype granulosa cell tumors can be accurately diagnosed solely based on the examination of H\&Estained slides; however, even in expert gynecopathology environments there will always be a number of challenging cases in which adult-type granulosa cell tumor enters the differential diagnosis but a definitive diagnosis is not possible based on the examination of routine H\&E-stained slides. Following up on the results of our previous study, ${ }^{3}$ the current report confirms the utility of a diagnostic strategy including FOXL2 immunohistochemistry and mutation testing in equivocal cases in confirming or excluding a diagnosis of adult-type granulosa cell tumor. The presence of FOXL2 mutation appears to conclusively support a diagnosis of adult-type granulosa cell tumor, based on the available evidence; however, a FOXL2 wildtype result cannot be used to definitively suggest an alternate diagnosis.

One of the main diagnostic problems encountered in practice, and highlighted in this case series, is that of thecoma vs adult-type granulosa cell tumors with diffuse pattern and luteinized cells. Thorough sampling may reveal more typical and diagnostic adulttype granulosa cell tumor, in which case the diagnosis is straightforward. In small tumors, in particular, the appearance may be uniform throughout; Table 2 lists 


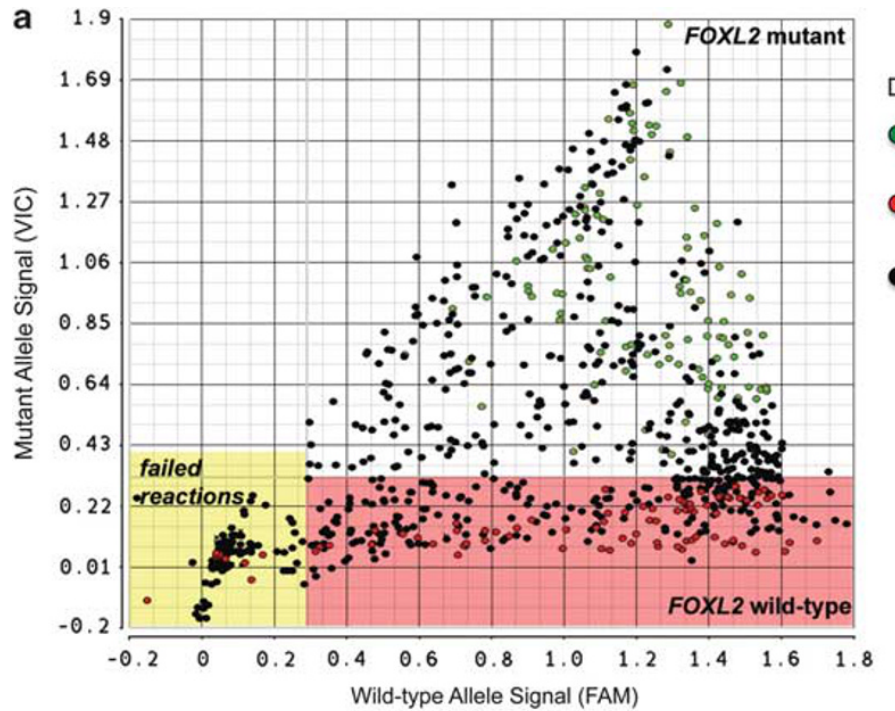

\section{Data Category \\ Optimal \\ Conditions \\ O Negative \\ Controls \\ - All other \\ replicates}

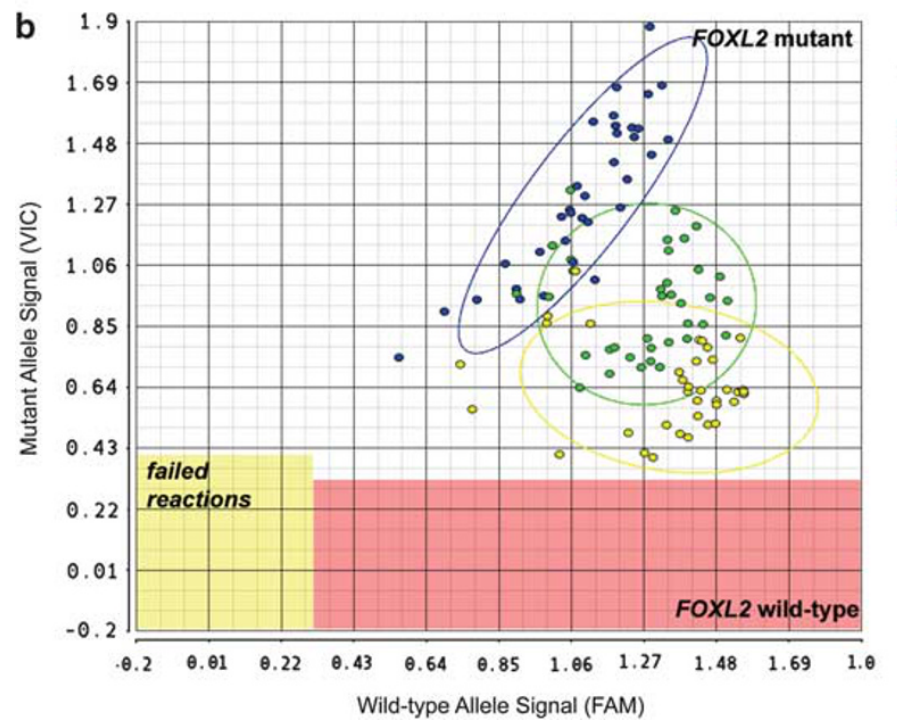

Tumour Cellularity

- $100 \%$

$50 \%$

○ $25 \%$

Figure 4 TaqMan allelic discrimination assay plots of signal intensity, the chart area is shaded to represent regions where samples could reliably be predicted to be positive or negative (red shade) for FOXL2 mutation or assay failure (yellow shade), see Materials and methods for threshold levels. (a) Scatter plot shows all samples, replicates, dilutions, and DNA inputs. Data show an exceptionally wide distribution despite the presence of FOXL2 mutant DNA in virtually all data points, supporting that standardized assay guidelines should be established to improve specificity and sensitivity of FOXL2 mutation detection. (b) Scatter plot shows only samples, replicates, dilutions, and DNA inputs that fall within our recommended guidelines (DNA input 5-10 ng and tumor content $>25 \%$ ).

the features of thecoma and luteinized adult-type granulosa cell tumors, and the challenges in differential diagnosis become readily apparent. Apart from FOXL2 mutation status, the only distinguishing feature is reticulin staining (which is a precarious basis for diagnosing a benign (thecoma) vs malignant (adult-type granulosa cell tumor) tumor). We previously reported a case that was diagnosed, after gynecological pathology review, as thecoma, but recurred 2 years later with histological features of adult-type granulosa cell tumor. ${ }^{3}$ Both the original tumor and the recurrence were FOXL2 mutation positive, leading us to conclude that the tumor was misdiagnosed originally, and propose that the rare cases diagnosed as malignant thecoma in the past may have been luteinized adult-type granulosa cell tumors. A correct diagnosis of adult-type granulosa cell tumor in these cases does not change treatment, but does allow for appropriate follow-up.

In another even more compelling case, a relapsed adult-type granulosa cell tumor was mistaken for high-grade serous carcinoma and the patient started on carboplatin and paclitaxel combination chemotherapy. Although several pathologists, all of them aware of a previous adult-type granulosa cell tumor in the patient history, were consulted, this tumor was misclassified due to its pleomorphism, inhibin negativity and strong p53 expression by immunohistochemistry. FOXL2 mutation testing, which was positive in both the original as well as 
Table 2 Features of thecoma and luteinized adult-type granulosa cell tumors

\begin{tabular}{ll}
\hline Thecoma & $\begin{array}{l}\text { Luteinized adult-type } \\
\text { granulosa cell tumor }\end{array}$ \\
\hline - Uniform cells & - Uniform cells \\
- Eosinophilic cytoplasm & - Eosinophilic cytoplasm \\
- Low mitotic rate & - Low mitotic rate \\
- FOXL2, inhibin and calretinin & - FOXL2, inhibin and \\
positivity & calretinin positivity \\
(immunohistochemistry) & (immunohistochemistry) \\
- Reticulin staining around & - Reticulin staining \\
individual tumor cells & surrounds nests of cells \\
& - Positive for FOXL2 \\
& mutation
\end{tabular}

relapsed tumor, confirmed a diagnosis of anaplastic adult-type granulosa cell tumor. The p53 immunohistochemistry in this case was misleading; although uncommon, strong p53 immunostaining can be seen in adult-type granulosa cell tumors; ${ }^{11,12}$ p53 was confirmed to be mutated in this case, in both the original tumor and recurrence. Similarly, negative inhibin immunostaining can be seen rarely in adult-type granulosa cell tumors, ${ }^{3}$ especially in small tumor samples.

In summary, we have provided clear procedural guidelines for FOXL2 mutation testing, which will allow accurate FOXL2 mutation testing on formalinfixed paraffin-embedded clinical samples. In cases where a diagnosis of adult-type granulosa cell tumor is a consideration and unequivocal diagnosis is not possible based on routine stains, FOXL2 mutation testing should be undertaken.

\section{Acknowledgements}

This project was supported by OvCaRe BC, and received funding from the Michael Smith Foundation for Health Research, the British Columbia Cancer Foundation, and the Vancouver General Hospital-University of British Columbia Hospital Foundations. Without the help of our colleagues, who contributed cases to this study, this work would not have been possible. We thank Dr Dave Lesack, Dr Naomi Golonka, Dr Daniel Chiapetta, Dr Julie Irving, Dr Vincent Scali, Dr Martin Kobel, Dr Maire A Duggan, Dr Valerie Dube, Dr Kurosh Rahimi, Dr Laurie Russell, Dr Marc Dupre, Dr Travis
Ogilvie, Dr Kay Park, Dr Dirk van Niekerk, Dr Guangming Han, and Dr Brinda Balachandra.

\section{Disclosure/conflict of interest}

The authors declare no conflict of interest.

\section{References}

1 Shah SP, Kobel M, Senz J, et al. Mutation of FOXL2 in granulosa-cell tumors of the ovary. $\mathrm{N}$ Engl J Med 2009;360:2719-2729.

2 Schrader KA, Gorbatcheva B, Senz J, et al. The specificity of the FOXL2 c.402C > G somatic mutation: a survey of solid tumors. PLoS One 2009;4:e7988.

3 Al-Agha OM, Huwait HF, Chow C, et al. FOXL2 is a sensitive and specific marker for sex cord-stromal tumors of the ovary. Am J Surg Pathol 2011;35:484-494.

4 Quach N, Goodman MF, Shibata D. In vitro mutation artifacts after formalin fixation and error prone translesion synthesis during PCR. BMC Clin Pathol 2004;4:1.

5 Jamieson S, Butzow R, Andersson N, et al. The FOXL2 C134W mutation is characteristic of adult granulosa cell tumors of the ovary. Mod Pathol 2010;23: 1477-1485.

6 Kim MS, Hur SY, Yoo NJ, et al. Mutational analysis of FOXL2 codon 134 in granulosa cell tumour of ovary and other human cancers. J Pathol 2010;221:147-152.

7 Kim T, Sung CO, Song SY, et al. FOXL2 mutation in granulosa-cell tumours of the ovary. Histopathology 2010;56:408-410.

8 D'Angelo E, Mozos A, Nakayama D, et al. Prognostic significance of FOXL2 mutation and mRNA expression in adult and juvenile granulosa cell tumors of the ovary. Mod Pathol 2011;24:1360-1367.

9 Kim HS, Byun SH, Lee BM. Effects of chemical carcinogens and physicochemical factors on the UV spectrophotometric determination of DNA. J Toxicol Environ Health A 2005;68:2081-2095.

10 Wilfinger WW, Mackey K, Chomczynski P. Effect of $\mathrm{pH}$ and ionic strength on the spectrophotometric assessment of nucleic acid purity. Biotechniques 1997;22: 8-81.

11 Kondi-Pafiti A, Grapsa D, Kairi-Vassilatou E, et al. Granulosa cell tumors of the ovary: a clinicopathologic and immunohistochemical study of 21 cases. Eur J Gynaecol Oncol 2010;31:94-98.

12 Kusamura S, Derchain S, Alvarenga M, et al. Expression of p53, c-erbB-2, Ki-67, and CD34 in granulosa cell tumor of the ovary. Int J Gynecol Cancer 2003;13:450-457. 